\title{
Glycemic Index of Five Ghanaian Corn and Cassava Staples
}

\author{
Eunice Serwaa Yeboah', Jacob K. Agbenorhevi2,", Gilbert Owiah Sampson³ \\ ${ }^{1}$ Department of Biochemistry and Biotechnology, Kwame Nkrumah University of Science and Technology, Kumasi, Ghana \\ ${ }^{2}$ Department of Food Science and Technology, Kwame Nkrumah University of Science and Technology, Kumasi, Ghana \\ ${ }^{3}$ Department of Hospitality and Tourism, College of Technology Education, University of Education, Winneba \\ *Corresponding author: jkagbenorhevi@yahoo.com, jkagbenorhevi.cos@knust.edu.gh
}

Received August 02, 2019; Revised September 03, 2019; Accepted September 10, 2019

\begin{abstract}
Glycemic index (GI) quantifies and measures the blood glucose raising effect of a food containing a specific amount of carbohydrate. Due to this concerns have been raised on the quality of carbohydrate and the indices that influence its metabolism. The objective of study was to investigate the effect of processing on the glycemic index of five Ghanaian corn and cassava staples. The research design was a cross over trial. Ten healthy subjects consisting of five males and five females were included in the study. Study subjects were served 50g of pure glucose containing $50 \mathrm{~g}$ of available carbohydrate and $200 \mathrm{ml}$ of pure water. Glucose which served as the reference food was given to subjects on two different occasions. The subjects were also served specific 50g of abolo, akple, kafa, local kokonte and processed kokonte on specific days. The glycemic index figures were assessed by using official methods and reported as mean for the ten study subjects. Locally made kokonte had the least GI of 7 followed by processed kokonte which had a GI of 18 whiles kafa had a low GI of 29. Abolo had a medium GI value of 58 and akple also had a medium glycemic index value of 69. There was no significant difference between the GI of locally made kokonte and processed kokonte ( $>$ > 0.05) indicating processing had no significant effect on the GI of kokonte.
\end{abstract}

Keywords: Glycemic Index, blood glucose, abolo, akple, kafa, kokonte

Cite This Article: Eunice Serwaa Yeboah, Jacob K. Agbenorhevi, and Gilbert Owiah Sampson, "Glycemic Index of Five Ghanaian Corn and Cassava Staples." Journal of Food and Nutrition Research, vol. 7, no. 8 (2019): 624-631. doi: 10.12691/jfnr-7-8-1.

\section{Introduction}

Carbohydrates are one of the three energy-yielding macronutrients required for the optimum functioning of the human body [1]. They provide energy for the body, especially the brain and the nervous system. The energy is also used for functions like heartbeat, digestion, breathing, regulating of blood glucose and sparing the use of proteins for energy [2]. An enzyme, amylase, breaks down the carbohydrates into glucose that is used for energy [3,4].

Most Ghanaian diets are carbohydrate-based and most families plan their meals around them. Sources of carbohydrates include maize, cassava, rice, millet and yam [1,5]. Carbohydrates vary in terms of their physical structure, chemical forms, particle size and fiber content which instigate different plasma glucose and insulin response [6]. Contrary to the general dogma that, diabetes is wealthy country's disease, diabetes mellitus (type 2 diabetes) is gradually becoming one of the nutritional problems in developing countries especially in sub-Saharan Africa [7] and this has become a public health concern in recent years.

Research has established that conscious dietary management is a necessity in obtaining an improved glycemic control to lessen the possibility of diabetic complications and to lengthen life span [8]. An amelioration of glycemic control by equalizing dietary intake with insulin levels is a main focal point in the nutritional management of diabetes [9]. Therefore, the way forward to maintain this balance is glycemic index and glycemic load [10]. The categorization of the rate at which ingested carbohydrates are broken down into sugars i.e. glucose is an estimation of its glycemic index [5]. This physiologic response to carbohydrate can be measured by GI indexes which collate plasma glucose to distinct foods with the response instigated by the same quantity of carbohydrate source, usually white bread or pure glucose. The glycemic index of foods are categorized on a scale of zero (0) to hundred (100) with 100 assigned to foods with a high glycemic index and 0 assigned to foods with a low glycemic index. Carbohydrate foods that are speedily broken down into glucose after eating are classified as a high glycemic index where as those that take a long time to convert into glucose are also classified as low glycemic index [5]. In addition to the two categories, there is a third group called medium glycemic index with GI values

between 56-59 [5]. Factors that can influence the GI of a food include processing, variety, methods of cooking, ripeness, amylose to amylopectin ratio, dietary fibre and 
storage time [11]. In determining the glycemic index of a carbohydrate food, the postprandial glycemic response of the food is measured against a reference food [12]. In Ghana and other developing countries, there is limited knowledge on the glycemic index of various staples. This study therefore sought to investigate the effect of processing on the glycemic index of five corn and cassava staples.

\section{Methodology}

The research was endorsed by the Committee on Human Research Publication and Ethics of the Kwame Nkrumah University of Science and Technology School of Medical Sciences/Komfo Anokye Teaching Hospital, 10 healthy individuals were taken on into the clinical trial. They consisted of 5 males and 5 females. They included nondiabetics between the ages of 20 years to 50 years. These individuals agreed to take part in the research and were also enrolled in line with the [12] commended procedure for the determination of the glycemic index. All subjects were oriented before the data collection procedure began. They were informed and made aware about what the research entailed. They were asked to stay away from smoking and drinking, any fatiguing activity before and during the time or period of study. All ten individuals who took part in the data collection were made to undergo a 10-14 $\mathrm{h}$ fast from the time they took their last meal the previous night to morning of testing. All subjects reported to the Sanford Hospital, Madina at 6:45 to 7:00 am. The reporting time and venue was the same for both reference and test foods.

The subjects had their weight and height taken using a bathroom scale and a stadiometer without their shoes or any heavy object on. The average weight and heights were taken and used for analysis. After the weights and heights were checked, the time each subject took their last meal was asked and recorded. This was done to know if participants had undergone the 10-14 $\mathrm{h}$ prior to testing. Capillary blood was taken from each participant to test for the FBS using a glucometer. After the FBS was done, a glucose solution made from $50 \mathrm{~g}$ glucose and $200 \mathrm{~mL}$ of water was given to each subject or participant. The stop watches were started when subjects started to drink the glucose solution. The glucose solutions were taken within a 5 min period. The time each participant began to drink the glucose solution was recorded. Fifteen (15) minutes after consuming the glucose solution the reference sample, participants had their thumps pricked to check or test for blood glucose level. After that, samples were taken from all subjects at the 30th, 45th, 60th, 90th and 120th min as well to check or test for the glucose concentration in $\mathrm{mmol} / \mathrm{L}$. This lasted for 2 h. On reporting, FBS of each respondent were measured, after which they were given measured amounts of test foods containing $50 \mathrm{~g}$ available carbohydrate portion (calculation of available carbohydrate portions were based on proximate analysis done by [13]. All test foods except abolo were eaten with $140 \mathrm{~g}$ of the groundnut soup and $30 \mathrm{~g}$ of beef whiles abolo was eaten with $30 \mathrm{~g}$ of anchovies. The reference food, glucose was administered a second time to the subjects on the fourth testing session. Five Ghanaian corn and cassava staple foods (abolo, akple, kafa, local and processed kokonte) prepared following standard indigenous preparation methods were tested under the same preconditions and procedure. Locally made and processed kokonte were prepared from cassava flour which was kneaded continuously in hot water to form a palp. Abolo was prepared from fermented dough, sugar and flour which were mixed together and steamed. Kafa was prepared from corn flour which was mixed in hot water, stirred continuously to form a palp and left to cool. Akple was also prepared from corn flour and stirred continuously in hot water to form a palp.

\section{Data Analysis}

The incremental area under the glucose response curves (IAUC) were calculated using the trapezoid rule as recommended by [12]. The area under the fasting baseline was ignored in the calculation. All GIs that were 2SD above or below the mean GI value for a given test was ignored as an outlier [14].

The IAUC for each test food was expressed as a percentage of the mean IAUC of the glucose which was the reference food used. The Glycemic index of each test food was calculated as the mean GI as obtained by each subject in the study that consumed the test food. Foods were classified as low, medium, or high GI according to the following: GI values $\leq 55$, Low GI; GI of 56-69, Medium and GI $\geq 70$, High GI $[5,15,16]$.

The glucose response curves were plotted with the Graph Pad Prism software version 5.00.

Data was analyzed using Microsoft Excel and Statistical Package for Social Sciences (SPSS) software version 20.

\section{Results and Discussion}

\subsection{General Characteristics of Subjects}

Ten Ghanaian subjects were enrolled in the research for the selected test meals. They consisted of 5 males and 5 females. The mean age, weight, height, body mass index and waist circumference are as follows; $23.10 \pm 2.60$, $64.16 \pm 7.9 \mathrm{~kg}, 161.40 \pm 6.04 \mathrm{~cm}, 24.39 \pm 3.1$ and $74.6 \pm 6.9 \mathrm{~cm}$.

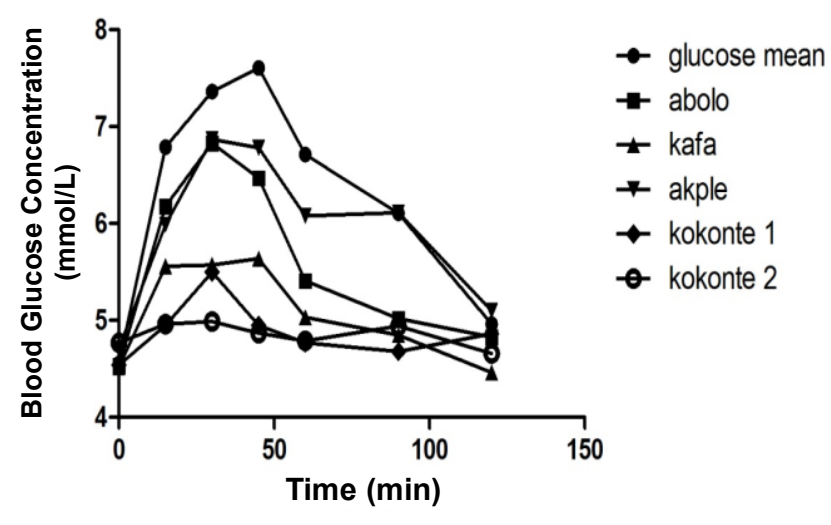

Figure 1. Mean glycemic responses elicited by study subjects after consumption of $50 \mathrm{~g}$ available carbohydrates portions of all test foods

Even though the glycemic index of both locally made kokonte and processed kokonte are low there was no significant difference between the incremental areas under the curve (AUC) for both at $95 \%$ confidence interval. Figure 1 shows mean glycemic responses elicited by study 
subjects after consumption of $50 \mathrm{~g}$ carbohydrates portions of all test foods.

The glycemic index profile for $120 \mathrm{~min}$ after a duplicate consumption of $50 \mathrm{~g}$ of pure glucose (reference food) with $200 \mathrm{~mL}$ of pure water was assessed in ten healthy participants. The average peak after consumption of glucose solution was noted at $45^{\text {th }}$ min from glucose consumption. The average fasting blood sugar levels before the consumption of the test foods(corn staples) were similar ( $\mathrm{p}>0.05$ ). The average peaks after consumption of abolo and akple was seen at the $30^{\text {th }}$ min where the average peak after consumption of kafa was also seen at the $45^{\text {th }}$ min from consumption of the test foods. The average peak after consumption of the two cassava staples (locally made kokonte and processed kokonte) was seen at the $30^{\text {th }} \mathrm{min}$.

\subsection{The GI Values Of Test Meals}

The current study investigate the GI of sampled food and results are displayed in Table 2. The two cassava staples studied, i.e., locally made kokonte and processed kokonte had a relatively low GI values of 7 and 18, respectively. Among the corn staples, kafa had the lowest GI where as abolo and akple had medium glycemic figures 29,58 and 69 , respectively according to [17].

Most Ghanaian meals are mainly composed of carbohydrate [18] and grouping them according to their distinct glycemic response has wiped away the notion that foods that are rich in carbohydrates are not suitable for persons with metabolic diseases such as diabetes and obesity. Studies have shown that carbohydrates are of different quality $[1,5]$. According to a study conducted by Bornet et al. [19], even though glucose has a nauseating effect after it has been ingested, it remains the reference material that has no variation in its preparation as compared to white bread which showed different mode of preparation in different study areas. The Ghanaian staples which had their glycemic index assessed and tested were abolo, akple, kafa, locally made kokonte and processed kokonte. About $140 \mathrm{~g}$ of groundnut soup and $30 \mathrm{~g}$ of beef (cow meat) were served with the test food except abolo which was served with $30 \mathrm{~g}$ of anchovies (locally called one man thousand). The glycemic index of beef and groundnut soup and the anchovies were tested differently to check and verify in they had any effect or impact on the test foods they were consumed with. Among the foods, akple had the highest glycemic index figure of 69 followed by abolo which had a medium glycemic index figure of 58, whereas kafa, locally made kokonte and processed kokonte had low glycemic index figure of 29, 7 and 18, respectively. Groundnut soup had a low GI of 4 whereas anchovies had a glycemic index of 0.9 .

In order for plant foods to be ready for human consumption, they undergo some series of processing methods. These processing methods include cooking (boiling, roasting, frying, steaming, baking), drying, mashing, grinding into flour and fermentation [20]. In this study all test foods were boiled except abolo which was further fermented and steamed.

Table 1. Incremental Area Under the Curve of Test Foods and Reference Food of Participants

\begin{tabular}{|c|c|c|c|c|c|c|}
\hline *Subjects & Glucose & Abolo & Akple & Kafa & Kokonte (Processed) & Kokonte (Locally Made) \\
\hline $\mathrm{CC} 11$ & 161.58 & 141.8 & 90.16 & 50.36 & 23.48 & 0.2187 \\
\hline LA20 & 223.05 & 100.5 & 163.6 & 75.44 & 24.66 & 0 \\
\hline OF30 & 248.25 & 139.5 & 123.0 & 73.31 & 69.75 & 43.73 \\
\hline JE40 & 250.6 & 209.3 & 219.0 & 143.3 & 182.3 & 57 \\
\hline PK50 & 226.88 & 203.3 & 111.4 & 147.5 & 21.9 & 40.75 \\
\hline JA60 & 210.05 & 162.0 & 108.8 & 41.44 & 45.75 & 8.344 \\
\hline $\mathrm{AB} 70$ & 343.55 & 104.3 & 234.8 & 89.36 & 113.3 & 72 \\
\hline SA80 & 118.8 & 51.32 & 104.2 & 8.804 & 0 & 25 \\
\hline BE90 & 221.85 & 57.25 & 65.38 & 38.59 & 3.375 & 10.59 \\
\hline JN10 & 237.4 & 141.8 & 374.3 & 123 & 88.16 & 10.87 \\
\hline Mean & $225.1 \pm 5.6$ & $131.1 \pm 3.8^{\mathrm{BC}}$ & $165.5 \pm 9.2^{\mathrm{CD}}$ & $79.1 \pm 6.7^{\mathrm{AB}}$ & $57.27 \pm 7.4^{\mathrm{AB}}$ & $26.85 \pm 5.21^{\mathrm{A}}$ \\
\hline
\end{tabular}

*Codes for subject recruited for the study. ${ }^{\text {A-D }}$ Mean values having different superscripts differ significantly $(p<0.05)$.

Table 2. Classification of selected staples as a function of GI

\begin{tabular}{|c|c|c|c|c|c|c|}
\hline No. & Food Item & GI Min (\%) & GI Max (\%) & GI \% & $\mathbf{S E}$ & GI Class \\
\hline 1 & Glucose & 100 & 100 & 100 & 0.0 & High \\
\hline 2 & Abolo & 25 & 89 & $58^{\mathrm{BC}}$ & 7.5 & Medium \\
\hline 3 & Akple & 29 & 157 & $69^{C}$ & 11.8 & Medium \\
\hline 4 & $K a f a$ & 7 & 65 & $29^{\mathrm{AB}}$ & 5.8 & Low \\
\hline 5 & Kokonte (local) & 0.0 & 22 & $7^{\mathrm{A}}$ & 2.9 & Low \\
\hline 6 & Kokonte (processed) & 0.0 & 72 & $18^{\mathrm{A}}$ & 6.8 & low \\
\hline
\end{tabular}

GI values having different superscripts differ significantly $(p<0.05)$. 
Basically for most foods, boiling is known to raise glycemic index as a result of a higher rate of gelatinization which enhances starch break down (digestibility) and raise glycemic response. Boiling disrupts the amylose and amylopectin structures of the starch by making it more available and easily broken down by digestive enzymes [16,21]. Among the corn staples, kafa had the lowest GI whiles abolo had a medium glycemic index figure of 58 and abolo having the highest glycemic index figure of 69 (Table 2). Comparing their fibre contents per $100 \mathrm{~g}$, abolo had the highest crude fibre, $0.6 \mathrm{~g}$ followed by akple and kafa which had the lowest crude fibre of $0.3 \mathrm{~g}$. The lowest GI obtained by kafa among the three corn staples was not surprising because it had the lowest available carbohydrate per $100 \mathrm{~g}$ and had the highest crude fibre.

The function of fibre in the breaking down of food and gastric emptying has deeply been delved into in numerous researches depicting its role in lengthening gastric emptying [22]. The lengthening of gastric emptying also has an effect on glucose response by the body $[21,23]$. This therefore implies that, large amounts of dietary fibre may not reduce glycemic response but also prevent colon cancer [23]. Hence it can be stated that foods that have a low glycemic index which contain high amounts of fibre may be capable of preventing colon cancer.

Another factor that resulted in kafa having a low GI can be attributed to the fact that right after boiling, it was left to cool completely at room temperature. When starches are cooked and cooled, the crystalline form within the food transforms into resistant starch which is more difficult to be broken down [24]. Crystallinity to gel can occur and it is normally referred to as retrograded starch. These structures that are formed are insoluble ant not susceptible to hydrolysis in the small intestine [25].

Akple recorded a medium glycemic index value due to the fact, among all the three corn staples studied, it had the lowest the amount of dietary fibre of $0.3 \mathrm{~g}$ per $100 \mathrm{~g}$ and even with its specific amount that contained the $50 \mathrm{~g}$ of available carbohydrate, it still had the lowest dietary fibre content of $0.71 \mathrm{~g}$. In the processing of corn to make akple, it was grounded, milled into a fine powder and sieved to remove all unwanted particles. These processing methods could be contributing factors to the reason why it had the lowest quantity of dietary fibre both per $100 \mathrm{~g}$ and its specific quantity which contained $50 \mathrm{~g}$ of available carbohydrate. The presence of low amount of dietary could be a reason why akple had a medium glycemic index figure.

In the preparation of akple, the corn flour was mixed with some amount of cold water and added to boiling water on fire. This mixture was divided into two parts and the rest was left on fire to boil again. The other half was left to cool for some few minutes. Corn flour was added to the boiling mixture on fire and mixed very well to prevent the formation of lumps. The remaining mixture that was left to cool was added to the mixture on fire and kneaded. Gelatinization of starch occurred when heat was applied to the mixture on fire in the process of boiling. When the mixture was divided into two and the second part was left to cool for some few minutes, retrogradation occurred. Since mixture was not allowed to cool completely, few amounts of resistant starches were introduced and are very difficult to be broken down by digestive enzymes since they are less susceptible to them. This could account to the reason why akple had a medium glycemic index.

The preparation of abolo differed from all the three corn staples. Aside that, abolo had the highest amount of fibre content of $0.6 \mathrm{~g}$ per $100 \mathrm{~g}$ and the second highest amount of fibre content of $1.04 \mathrm{~g}$ per its specific quantity that contained $50 \mathrm{~g}$ of available carbohydrate. Abolo was prepared from half-cooked corn dough (aflata) and raw corn dough with little sugar and flour. These ingredients were mixed together with water to form dough. The dough was allowed to rise overnight. The product was molded into sizeable portions and wrapped in leaves and steamed for about $45 \mathrm{~min}$. Maize was soaked for some few days in water for fermentation. Part of this corn dough was used to prepare the aflata (half cooked corn dough). The raw corn was then mixed with the half cooked dough together with little amount of sugar and flour. The mixture was then left overnight to rise. The final product was then steamed. Fermentation occurred as a result of soaking the corn in water and leaving the mixture to rise overnight. Through the fermentation process, some by products such as some organic acids were produced. Acetic acid is a type of organic which is formed during to the process of sourdough fermentation. Acetic acid is normally classified as part of a normal diet [26]. The preparation of abolo demands a partial cooking of fermented dough, followed by cooling to mix with uncooked dough, flour and sugar, leaving mixture overnight to rise, molding into desirable sizes and then finally steamed.

Acid which was produced during the process of fermentation accounted for the taste and flavor of abolo. This explains why abolo has a sour taste. These acids influenced the glycemic response of the test food. A previous study showed that acetic acid and addition of fermented products to foods enhances glycemic control [27]. It was also reported that the presence of acetic acid in foods lowers glycemic response by prolonging gastric emptying [27]. The acetic and other acids which are produced in the fermentation of corn and dough during the preparation of abolo could have could have reduced its glycemic response by prolonging gastric emptying. Also allowing the half cooked dough to cool before it was mixed with other substances enhanced retrogradation of starch which could introduced some amounts of resistant starches which are normally difficult to be digested or broken down by the digestive enzymes. This could have influenced the glycemic response and glycemic index of abolo.

The addition of flour could have also affected the glycemic index of the tested food. Flour was produced as result of milling of corn into a fine powder. It has been reported that the way a particular food is processed has an impact on its glycemic index $[28,29,30]$. Starches which are normally found in most carbohydrates exist in large forms of granules. During the processing these granular structures are destroyed so that the amylose and amylopectin macromolecules become more available for hydrolysis. Grinding of corn to produce flour destroys its outer layer, granules and increases digestion. Shifting of flour to remove unwanted particles eliminated the dietary fibre content in flour therefore making it easy to digest [28,29,30].

Glycemic index of foods are usually influenced by the content or composition of sugar present in the food. For 
instant, sucrose which is composed of glucose and fructose has a lower glycemic index than glucose. The presence and the molecule make up of fructose in sucrose is the reason why it elicits a low blood glucose response. In addition, sucrose has a medium glycemic index figure of 68 whiles glucose has a high glycemic index figure of 100 [31]. Table sugar or granulated sugar (simple carbohydrate) was used in the preparation of abolo. It is normally referred to as sucrose, a disaccharide, which is composed of both fructose and glucose. Sucrose is an easily absorbed carbohydrate (macronutrient) that yields a quick source of energy by resulting in a rapid raise in blood glucose levels upon consumption.

Even though sucrose has lower glycemic index, it has been discovered that it speeds up the rate of digestion when it is added to food. This makes food easily digested and absorbed rapidly in to the blood stream. This could have resulted in the medium glycemic index figure of abolo. Slow cooking methods such as baking and steaming normally yields lower glycemic index unlike quick methods of cooking such as boiling, pressure cooking and microwave cooking. Steaming is a slow method of cooking which works by boiling water continuously and allowing it vaporize into steam. Steam then transport heat to near food, thus cooking the food. The food is kept separate from the boiling water but has a direct contact with the steam resulting in a moisture texture to the food. Most food nutrients are retained in steaming since it is a slow method of cooking food. In the preparation of abolo, the steam from the boiling water was used to cook the food. This could have resulted in a lower gelatinization of starch since boiling water did not come into contact with the food directly but rather the steam from the boiling water cooked the food. This resulted in lesser disruptions of the amylose and amylopectin quantities making it less available to digestive enzymes to break them down. This slow method of cooking could result in the reason why abolo had a medium glycemic index figure.

Cassava is presumed to induce an increased glucose response on ingestion since it's starch granules consists largely of amylopectin which is more branched and readily digestible by amylases. However, the nutrient content of cassava differs depending on the cooking method. Locally made kokonte as well as processed kokonte were prepared using cassava through the process of boiling. Even though both cassava staples had lower glycemic index values of 7 and 18, respectively, their total dietary fibre content per $100 \mathrm{~g}$ as well as their specific quantities that contained $50 \mathrm{~g}$ of available carbohydrate differed. Locally made kokonte had a total dietary fibre content of $1.1 \mathrm{~g}$ per $100 \mathrm{~g}$ and $0.66 \mathrm{~g}$ per its specific quantity that contained $50 \mathrm{~g}$ of available carbohydrate $(60 \mathrm{~g})$. Processed kokonte had no amount of dietary fibre both per $100 \mathrm{~g}$ as well as its specific quantity that contained $50 \mathrm{~g}$ of available carbohydrate $(60 \mathrm{~g})$. The same quantity of $60 \mathrm{~g}$ was measured for both locally made and processed kokonte so that their variations and glycemic index could be measured and compared weight for weight. This can account for the reason why processed kokonte had a high glycemic index figure of 18 whiles locally made kokonte had a glycemic index of 7 even though both staples had low glycemic index values. This explains the function of dietary fibre in controlling the way food is broken down (digested) and absorbed into the bloodstream and also delaying gastric emptying. Since processed kokonte had no dietary fibre, it was rapidly digested and absorbed in to the blood stream causing a rapid increase in the blood glucose level than locally made kokonte.

Just like the other corn staples, cassava went through some series of processing methods and then finally boiled before consumption. These series of processing methods include peeling, washing, cutting into specific sizes, sun drying/fermentation, pounding, milling and sieving/shifting. During the process of sun drying, fermentation occurred and this introduced some amount of acetic acid into the cassava [32,33]. Some microorganisms such as amylolytic enzymes and organic acids such as acetic acids are formed during cassava fermentation to [34,35]. This could be a contributing factor to the reason why both processed and locally made kokonte had lower glycemic index value.

According to Brand et al. [36], sun drying and cooling affects starch breakdown and in turn affects glycemic response and glycemic index figures. The hot temperature treatment and cooling cycles which occurred during the cassava flour production could have some amounts of retrograded starches. The presence of these starches in flour makes it less susceptible to digested by the digestive enzymes. These however, reduce glycemic response and in turn reduce the GI value. This could also account for the reason why both locally made and processed kokonte had low GI values.

During the preparation of both processed and locally made kokonte, the cassava flour was added to boiling water and kneaded. As time went on more flour was added to the mixture and kneaded to prevent the formation of lumps and achieve the desired thickness. As time went on the fire was reduced to prevent food from burning. This in turn reduced the amount of heat which was applied to the food. The final product was taken from fire and allowed to cool for some few minutes. The reduction of heat during the process of preparation and cooling which occurred at the end cooking could have resulted in retrogradation and this could have introduced some amounts of resistant starches which are not normally susceptible to digestion by the digestive enzymes. This factor could also account for the reason both processed and locally made kokonte had low glycemic index values.

\subsection{Effect of Fibre on Glucose Response}

The availability of dietary present in a food has an impact on the glycemic response of a food. Dietary fibre has been noted to extend and lengthen gastric emptying and absorption of carbohydrate and also raising or improving satiety play an essential role in reducing the glycemic index of a food. The current study showed that fibre content of test foods varied significantly in their raw and processed states. This is due to the fact that processing had an effect on the total dietary fibre content. The fibre content of both cassava and maize in their raw states per $100 \mathrm{~g}$ are $1.8 \mathrm{~g}$ and $7.3 \mathrm{~g}$, respectively however in their processed states per $100 \mathrm{~g}$ of each test food, abolo had a fibre content of $0.6 \mathrm{~g}$, kafa $0.3 \mathrm{~g}$, akple $0.3 \mathrm{~g}$, locally made kokonte $1.1 \mathrm{~g}$ while processed kokonte recorded fibre. In their specific quantities that contain the $50 \mathrm{~g}$ of available carbohydrates, abolo had a fibre content of $1.04 \mathrm{~g}$, kafa $1.07 \mathrm{~g}$, akple $0.71 \mathrm{~g}$, locally made kokonte $0.66 \mathrm{~g}$ 
and processed kokonte had no fibre. Kafa had the highest dietary fibre content among the test foods and had a lower glycemic index figure as well. Even though processed kokonte had the lowest dietary fibre content, it still had a low glycemic index value. This goes a long way to buttress the point that glycemic response of foods is affected by other indices that will include but not limit the total quantity of fibre in the food item [5].

\subsection{Effects of Previous Meal on GI}

The glycemic index value and glycemic response can differ based on the meal eaten previously. For example, it has been noted that eating a diet that has a low glycemic index rather than a diet that has a high glycemic index has an important impact by reducing the post prandial level after the next meal and vice versa [37]. The quality of diet taken in the evening prior to GI determination may influence the test results or outcome. Fat tolerance is poorer following a carbohydrate-rich meal whiles glucose tolerance is poorer following a fat-rich evening meal [38]. He went further to explain that the impact of an evening meal macronutrient on fat tolerance is higher than the impact of glucose tolerance. However, the glycemic index of evening meals may sometimes have an impact on test results or outcome which is not based on the macronutrient content of a meal. Previous studies $[39,40]$ showed that evening foods that have a low glycemic index yield an enhanced and better glucose tolerance than evening meals that have a high glycemic index in the morning of testing. Prior to the days as testing subjects were oriented as to the time they have to take their last so as to undergo the 10-14hr fast but they were restricted in terms of the meals they should eat. It was discovered that two of the study subjects or participants consumed high fibre diets in the evening prior to the day of fasting. Subject SA80 consumed kenkey and okro stew in the evening prior to the testing of abolo. Though the study subject did not have the lowest glucose response for all the test foods, the IAUC of abolo for subject SA80 was the lowest. (51.32). Similar thing can be said of study subject BE90 who consumed brown rice and vegetable stew in the evening prior to the testing of kafa. This study subject had the lowest IAUC figure of 65.38 for kafa. For study subject JE40 who consumed kelewele a diet low in fibre and high in fat in the evening prior to the testing of processed kokonte, had the highest IAUC value of 182.3 for processed kokonte.

\subsection{Time and Duration of Fasting}

The specified extent of the fasting throughout the night is an essential factor that can affect the glycemic response. According to previous studies [41,42], the steady state often supposed to occur after the whole night fast is duration of essential variation or changes in the view of reducing plasma insulin concentration and raising lipolysis. In the present study, the subject SA08 who over fasted in the evening prior to the morning of testing processed kokonte had the lowest fasting blood sugar level of $3.5 \mathrm{mmol} / \mathrm{L}$.

\subsection{Effect of Portion Size}

It has been noted that a food item that has a larger portion size has a higher glycemic index value while a food item that has a small portion has a low glycemic index value. The portions of tests foods were $359 \mathrm{~g}, 238 \mathrm{~g}, 173 \mathrm{~g}$ and $60 \mathrm{~g}$, respectively. Both locally made and processed kokonte had the smallest portion sizes and had low GI values as well. In contrast, even though kafa had the largest portion size, it had a low glycemic index figure. Abolo had the second lowest portion size of $173 \mathrm{~g}$ but had a medium glycemic index figure. Apkle had the second highest portion size but had the highest glycemic index figure. Even though large portion sizes can yield a higher glycemic response and vice versa, when juxtaposing the glucose response of the same amount of available carbohydrate portions, the quality and processing indices play important roles [5].

\subsection{Effects of Soup, Meat and Fish Eaten Together with Test Food}

Due to the nature of the test foods they could not be eaten alone and therefore were served with other accompaniments. Abolo was served with $30 \mathrm{~g}$ of anchovies, whereas akple, kafa, kokonte (local and processed) were served with groundnut soup and beef. The glycemic index of a particular meal is usually based and influenced by the content of that particular food. It is mostly believed that various factors which includes the presence of fat [43], protein [44] and the presence of some acidic compounds $[27,45,46]$ in one way or the other influence or affects the glycemic index of a meal. When a particular food is consumed with other accompaniments, the glucose response to this meal is normally different than consuming that particular food alone without any accompaniment. Fat, carbohydrate, protein and other nutrients when consumed together with other test food have an effect on both glucose and insulin responses. But however, according to a study conducted by [47], the amount and quantity of carbohydrate is what has an impact on the glucose response to a meal.

Insulin and glucose response to a carbohydrate food varies with the amount of fat, protein or both with which it's ingested. Fat and protein may influence gastric emptying and insulin secretion, but the effects of glycemic index are not seen unless there are relatively large amount of fat and protein per $50 \mathrm{~g}$ of available carbohydrate. For fat and protein to affect the glycemic index of a meal it has must have total quantities of about $30 \mathrm{~g}$ of protein and about $50 \mathrm{~g}$ of fat [48]. Further studies was made into to the groundnut soup with beef and anchovies to find out if it had an impact on the glycemic index of test foods it was eaten with. At the end of the study, it was discovered that groundnut soup had a low GI value of 4 whereas anchovies also had a low GI of 0.9. To get the actual GI value for the test foods, the GI of the accompaniments (Table 3) were subtracted from that of test foods to obtain the GI values without the accompaniments (Table 4). The GI of groundnut soup with beef was subtracted from the GI of akple, kafa, locally made and processed kokonte whereas the GI of anchovies was subtracted from the GI of abolo.

Table 3. Glycemic Index of groundnut soup with beef and anchovies

\begin{tabular}{lcc}
\hline Food Item & GI value & GI Class \\
\hline Groundnut soup with beef & 4 & low
\end{tabular}


Anchovies

0.9

low

Table 4. Glycemic index of test meals with and without accompaniments

\begin{tabular}{lcc}
\hline Test foods & $\begin{array}{c}\text { GI with } \\
\text { accompaniments }\end{array}$ & $\begin{array}{c}\text { GI without } \\
\text { accompaniments }\end{array}$ \\
\hline Abolo & 59 & 58 \\
Akple & 73 & 69 \\
Kafa & 33 & 29 \\
Locally made kokonte & 11 & 7 \\
Processed kokonte & 22 & 18 \\
\hline
\end{tabular}

\section{Conclusion}

A low to high glycemic index values were obtained for the five Ghanaian corn and cassava staples (abolo, akple, kafa, local and processed kokonte) studied which indicate that carbohydrates are of various qualities and influence blood glucose differently. These factors should be highlighted in recommending diets for diabetics. The data yielded from the study has also showed that the glycemic index of individual foods should be assessed differently and not based on other food that has the same description.

\section{Conflict of Interest}

None.

\section{References}

[1] Lamothe, L.M., Le, K., Samara, R.A., Roger, O., Green, H. and Marce, K. (2017). The scientific basis of healthful carbohydrate profile. Critical Reviews in Food Science and Nutrition, 1-54.

[2] Mann, J., Cummings, J. H., Englyst, H. N., Key, T., Liu, S., Riccardi, G., et al. (2007). FAO/WHO Scientific Update on carbohydrates in Human nutrtion: conclusions. European Journal of Clinical Nutrition, 61 (1): 132-137.

[3] Hemery, Y., Rouau, X., Lullien-Pellerin, V., Barron, C. and Abecassis, J. (2007). Dry processes to develop wheat fractions and products with enhanced nutritional quality. Journal of Cereal Science, 46, 327-347.

[4] Hernot, D.C., Boileau, T.W., Bauer, L.L., Swanson, K.S. and Fahey, G.C. (2008). In vitro digestion characteristics of unprocessed and processed whole grains and their components. Journal of Agriculture and Food Chemistry, 56: 10721-10726.

[5] Eli-Cophie D., Agbenorhevi, J.K. and Annan, R.A. (2017). Glycemic Index of Some Local Staples in Ghana, Food Sciences \& Nutrition, 5(1):131-138.

[6] Jenkins DJ, Wolever TM, Taylor RH, et al. (1981) Glycemic index of foods: a physiological basis for carbohydrate exchange. Am J Clin Nutr; 34: 362-6

[7] Gning, S.B, Thiam, M., Fall, F., Ba-Fall, K., Mbaye, P.S \& Foucarde, L. (2007). Sugar Diabetes in Sub-Saharan Africa: Epidemiological Aspect, Difficulties of Management. Tropical Medicine, 67, (6): 607-611.

[8] Koussasi K.N., Tiahou G.G, Abodo F.R.J, Camara-Cisse M. \& Amani N.G, (2009). "Influence of the Variety and Cooking Method on Glycemic Index of Yam”, Pakistan Journal of Nutrition, 8, (7) 993-999.

[9] Kalergeris M., De Gandpre E. \& Anderson C. (2005). "The Role of Glycemic Index in the Prevention and Management of Diabetes: A Review and Discussion", Canada Journal of Diabetes, Vol.29, No.1, pp. 27-38.
[10] Mash, K. \& Brand-Miller, J. (2008) Glycemic Index Obesity, and Chronic Disease", American of Lifestyle Medicine, Vol.2, No.2, pp.142-150.

[11] Aston, L. M., Gambell, J. M., Lee, D. M., Bryant, S. P., \& Jebb, S A. (2008). Determination of the glycaemic index of various staple carbohydrate-rich foods in the UK diet. European Journal of Clinical Nutrition, 62, 279-285.

[12] FAO/WHO. (1998). Carbohydrates in human nutrition. Report of a Joint FAO/WHO Expert Consultation, (FAO Food and Nutrition Paper - 66). Food and Agriculture Organisation of United Nations, Rome.

[13] Eyeson, K. K., Ankrah, E. K., Sundararajan, A. R., Karinpaa, A., \& Rudzka, M. J. (1975). Composition of Foods Commonly Used in Ghana. Accra: Secretariat of the Council for Scientific and Industrial Research.

[14] Wolever, T. M., Vuksan, V., \& Jenkins, A. A. (2011) Determination of Glycemic Index of: Hand-Stretched Cheese Pizza. Toronto: Glycemic Index Laboratories Inc.

[15] Jenkins, D.J.A., Kendall, C.W.C.; Augustin, L.S.A. Franceschi, S., Hamidi, M, Marchie, A., Jenkins, A.L, and Axelsen, M. (2002) Glycemic index: overview of implications in health and disease. The American Journal of Clinical Nutrition, 76 (1): 266-273.

[16] Bahado-Singh, P. S., Riley, C. K., Wheatly, A. O., \& Lowe, H. I (2011). Relationship between Processing Method and the Glycemic Indices of Ten Sweet Potato (Ipomoea batatas) Cultivars Commonly Consumed in Jamaica. J Nutr Metab, 2-6.

[17] Jenkins AL, Jenkins DJ, Zdravkovitz U, Wursch P, Vuksan V. (2002). Depression of glycemic index by high levels of beta-glucan fiber in two functional foods tested in type 2 diabetes. Eur J Clin Nutr 56, 622-628.

[18] Eyeson, K. K. and Ankrah, E. K. (1975). Composition of foods commonly used in Ghana. Food Research Institute, Council for Scientific and Industrial Research, Accra, Ghana.

[19] Bornet, F. R., Costagliola, D., Blayo, A., \& et al, (1987) Insulinogenic and glycemic indexes of six starch-rich foods taken alone and in a mixed meal by type 2 diabetics. American Journal clinical Nutrtion , 45, 588-95.

[20] Omoregie E.S \& Osagie A.U. (2008). Glycemic Indicies and Glycemic Load of Some Nigerian Foods. Department of Biochemistry, Faculty of Life Sciences, University of Benin, P.M.B 1154 Benin City, Nigeria.

[21] Lin, M.-H. A., Wu, M.-C., Lu, S., \& Lin, J. (2010). Glycemic index, glycemic load and insulinemic index of Chinese starchy foods. World J Gastroenterology, 16 (39), 4973-4979.

[22] Holm, J., Lundquist, I., Bjorck, I., Eliason, A.C. and Asp, N.G (1988). Degree of starch gelatinization, digestion rate of starch in vitro and metabolic response in rats. American Journal of Clinical Nutrition. 47: 1010-1016.

[23] Silvester, K. R., Englyst, H. N., \& Cummings, J. H. (1995). Ileal recovery of starch from whole diets containing resistant starch measured in vitro and fermentation of ileal effluent. American Journal of Nutr, 62, 403-11.

[24] Annison G. \& Topping D.L. (1994). Nutritional role of resistan starch: Chemical Structure vs Physiological Function. Annu Rev Nutr; 14:297-320.

[25] Sievert D, Czuchajowska A, \& Pomeranz Y. (1991). Enzyme resistant starch.III. X-ray diffraction of autoclaved amylomaize. Cereal Chem; 68:86-91.

[26] Ostman, E., Granfeldt, Y., Persson, L., \& Bjorck, I. (2005). Vinegar supplementation lowers glucose and insulin responses and increases satiety after a bread meal in healthy subjects. European Journal of Clinical Nutrition, 59, 983-988.

[27] Liljeberg, H., \& Bjorck, I. (1998). Delayed gastric emptying rate may explain improved glycaemia. European Journal of Clin. Nutr, $52,368-371$

[28] O’Dea K, Nestel P.J, \& Antonoff, L. (1980). Physical factors influencing postprandial Glucose and insulin responses to starch. Am J Clin Nutr; 33:760-5

[29] Collier, G. \& O'Dea, K. (1982). Effect of physical form of carbohydrate on the postprandial glucose, insulin, and gastric inhibitory polypeptide responses in type 2 diabetes. Am J Clin Nutr; 36:10-4.

[30] ASPNG. (1987). Definition and analysis of dietary fibre. Scand J Gastroenterol Suppl; 129: 16-20.

[31] Pi, SFX. (2002). Glycemic Index and Disease. Am J Clin Nutri. 76:29085-2985. 
[32] Ascheri D.P.R. \& Vilela, E.R. (1995). Changes in cassava flour by fermentation in the manufacture of cookies. Pesq. Agropec. Bras., 30, 269-279.

[33] Cereda, M.P. \& Bonassi, I.A. (1985). Quality evaluation of commercial fermented cassava starch: Organic acids and water absorption. Rev. Bras. Manioc, 3, 21-30.

[34] Demiate, I.M., Dupuy, N., Huvenne, J.P., Cereda, M.P. \& Wosiaki, G. (2000). Relationship between banking behavior of modified cassava starches and starch chemical structure determined by FTIR spectroscopy. Carbohydr. Polym., 42, 149-158.

[35] Pereira, J., Ciacco, C.F., Vilela, E.R. $Q$ \& Texeira, L.S. (1999). Fermented starch in cookie making: study of alternative sources. Food Sci. Technol., 19, 287-293.

[36] Brand, J. C., Nicholson, P. L., Thorburn, A. W., \& Truswell, A. S. (1985). Food Processing and Glycemic index. American Journal of Clinical Nutrition, 42, 1192-1196.

[37] Frost, G.S. \& Dornhurst, A. (2005). Glycemic index. In: Encyclopedia of human nutrition, vol. 2, edn 2. Allan, L., Prentice, A. and Caballero B. Eds, Academic Press. pp 413-418.

[38] Robertson M.D, Henderson R. A, Vist, G. E \& Rumsey R.D.E (2002). Extended effect of evening meal carbohydrate/fat ratio on fasting and postprandial substrate metabolism. American Journal of Clinical Nutrition, 75, 505-510.

[39] Wolever T.M, Jenkins D.J, Ocana AM, Rao V.A \& Collier, G.R (1988b). Second-meal effect: low-glycaemic-index foods eaten at dinner improve subsequent breakfast glycaemic response. American Journal of Clinical Nutrition, 48, 1041-1047.

[40] Thorburn, A., Muir, J., \& Proitto, J. (1993). Carbohydrate fermentation lowers hepatic glucose output in healthy subjects. Metabolism, 42, 780-785.
[41] Klein S, Sakurai Y, Romijn JA \& Carroll RM (1993). Progressive alterations in lipid and glucose metabolism during short-term fasting in young adult men. American Journal of Physiology, 265 801-806.

[42] Samara J.S, Clark M.L, Humphreys S.M, Macdonald I.A \& Frayn K.N (1996). Regulation of lipid metabolism in adipose tissue during early starvation. American Journal of Physiology, 271, 541-546.

[43] Collier G \& O'Dea K (1983). The effect of coingestion of fat on the glucose, insulin, and gastric inhibitory polypeptide responses to carbohydrate and protein. American Journal of Clinical Nutrition 37, 941-944.

[44] Granfeldt Y., Bjorck I., \& Hagander B. (1991). On the importance of processing conditions, product thickness and egg addition for the glycaemic and hormonal responses to pasta: a comparison with bread made from 'pasta ingredients.' Eur J Clin Nutr; 45:489-99.

[45] Liljeberg H.G, Lonner C.H \& Bjorck I.M (1995). Sourdough fermentation or addition of organic acids or corresponding salts to bread improves nutritional properties of starch in healthy humans. Journal of Nutrition, 125, 1503-1511.

[46] Liljeberg H.G, Bjorck I.M. (1996). Delayed gastric emptying rate as a potential mechanism for lowered glycaemia after eating sourdough bread: studies in humans and rats using test products with added organic acids or an organic salt. Am J Clin Nutr; 64: 886-93.

[47] Wolever T.M.S \& Bolognesi C. (1996b). Prediction of glucose and insulin responses of normal subjects after consuming mixed meals varying in energy, protein, fat carbohydrate and glycaemic index. Journal of Nutrition 126, 2807-2812.

[48] Wolever, T. M., Katzaman-Relle, L., Jenkins, A. L., Vuksan, V., Josse, R., \& Jenkins, D. J. (1994). Glycaemic index of 102 complex carbohydrates in Patients with diabetes. Nutr. Res., 4, 651-669.

(C) The Author(s) 2019. This article is an open access article distributed under the terms and conditions of the Creative Commons Attribution (CC BY) license (http://creativecommons.org/licenses/by/4.0/). 